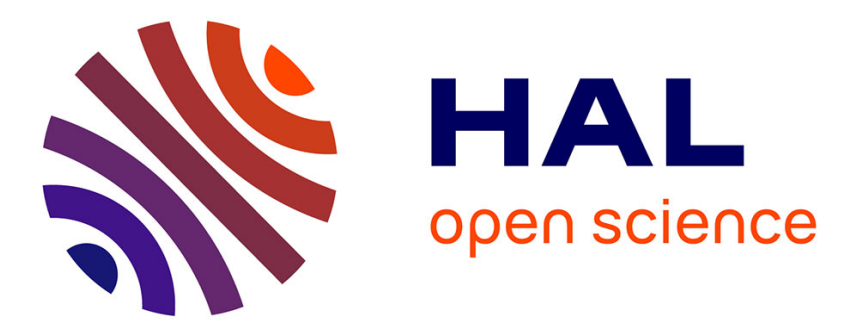

\title{
Two-component systems and toxinogenesis regulation in Clostridium botulinum
}

\author{
Chloé Connan, Michel R. Popoff
}

\section{To cite this version:}

Chloé Connan, Michel R. Popoff. Two-component systems and toxinogenesis regulation in Clostridium botulinum. Research in Microbiology, 2015, pii: S0923-2508(14)00261-7. 10.1016/j.resmic.2014.12.012 . pasteur-01115185

\section{HAL Id: pasteur-01115185}

\section{https://hal-pasteur.archives-ouvertes.fr/pasteur-01115185}

Submitted on 10 Feb 2015

HAL is a multi-disciplinary open access archive for the deposit and dissemination of scientific research documents, whether they are published or not. The documents may come from teaching and research institutions in France or abroad, or from public or private research centers.
L'archive ouverte pluridisciplinaire HAL, est destinée au dépôt et à la diffusion de documents scientifiques de niveau recherche, publiés ou non, émanant des établissements d'enseignement et de recherche français ou étrangers, des laboratoires publics ou privés.

\section{(ㅇ)(1) $\$$}

Distributed under a Creative Commons Attribution - NonCommercial - NoDerivatives 44.0 

2 3

4 6

7 8

9 10

\section{Two-component systems and toxinogenesis regulation in Clostridium botulinum}

Chloé CONNAN, Michel R. POPOFF*

Institut Pasteur, Unité des Bactéries anaérobies et Toxines, Paris, France

- corresponding author (mpopoff@ pasteur.fr)

Key words: Clostridium botulinum, toxin, regulation, two-component systems 
11

12

13

14

\section{Abstract}

Botulinum neurotoxins (BoNTs) are the most potent toxins ever known. BoNTs associate with non-toxic proteins to form complexes of various sizes. Toxin production is highly regulated through complex networks of regulatory systems involving an alternative sigma factor, BotR, and at least 6 two-component systems (TCSs). TCSs allow bacteria to sense environmental changes and to respond to various stimuli by regulating the expression of specific genes at a transcriptional level. This review aims to highlight the role of TCSs as a central point in the regulation of toxin production in $C$. botulinum.

(1)

2

3

.

25

26

\section{7}


Botulinum neurotoxins (BoNTs) are responsible for human and animal botulism, a rare but severe disease that causes a descendant flaccid paralysis which can be lethal if not treated. BoNT/A is the most potent toxin ever known with an estimated lethal dose of $0.3 \mathrm{ng} / \mathrm{kg}$ in mice by intraperitoneal route [1]. BoNTs are mostly produced by $C$. botulinum but also by atypical strains of other Clostridium species.

The first descriptions of botulism were reported in Germany in 1793 and this disease was linked to the consumption of blood sausages prepared from pork. Indeed, in its natural form botulism is mostly acquired after absorption of BoNTs from the digestive tract following the ingestion of food contaminated by $C$. botulinum and its toxin. BoNTs are metalloproteases that specifically cleave SNARE (N-ethylmaleimide sensitive factor (NSF) attachment protein receptor) proteins localized at motoneuron nerve endings leading to an inhibition of evoked acetylcholine secretion and thus the characteristic flaccid paralysis.

C. botulinum and the other BoNT-producing clostridia are obligate anaerobic Grampositive bacteria. Their ability to form spores enables them to survive for long periods of time under stressful environmental conditions. BoNT-producing clostridia are heterogeneous and are divided into 6 groups [2]. Strains from the different groups exhibit specific physiological properties that dictate their main localization in the environment, such as resistance to high $\mathrm{NaCl}$ concentration, temperature or extreme $\mathrm{pH}$ and nutrient availability [3]. For example, group II strains can grow and produce toxins at temperature as low as $3^{\circ} \mathrm{C}$ whereas group I strains, which include type A neurotoxin producing $C$. botulinum, do not synthesize toxins at temperatures below $10^{\circ} \mathrm{C}$. C. botulinum produces 7 BoNT types (A to G) based on their antigenic properties and many subtypes based on amino acid sequence variations [4]. An eighth toxinotype $(\mathrm{H})$ has recently been reported but awaits for further characterization [5].

Considering their physiological differences, limiting the proliferation of $C$. botulinum strains and toxin production has become a major issue in the food-processing industry, especially since the development of modified-atmosphere packaging (MAP) which strongly inhibits aerobic bacterial growth but has only limited effects on anaerobic bacteria [6]. Based on the high potency of BoNTs, understanding the factors that govern the toxinogenesis in $C$. botulinum and control of BoNT production notably in food processing are major challenge in the field.

BoNT production varies between strains, medium and culture conditions; thus it has rapidly become apparent that environmental factors play a central role in toxin production. Two-component systems (TCSs) allow bacteria to sense environmental changes and to adapt in response to various stimuli including chemical (temperature, $\mathrm{pH}$, ions), physical (oxygen 
pressure, osmolarity, redox state) and nutritional (glucose, tryptophan) stimuli by regulating the expression of specific genes at the transcriptional level. They are widespread among bacterial species and are involved in the control of gene expression of complex regulatory networks. For instance, recent evidence has shown that TCSs regulate cold tolerance in $C$. botulinum types $\mathrm{E}$ and $\mathrm{A}[7,8]$. It has also been demonstrated that TCSs are major regulatory systems for the control of virulence factor production in numerous intracellular or extracellular pathogenic bacteria such as Clostridium perfringens, Helicobacter pylori or Listeria monocytogenes (for review see [9]).

Although the molecular mechanisms of TCSs are well described, most of the stimuli that trigger regulation by TCSs are yet unknown. The involvement of TCSs in toxinogenesis in $C$. botulinum is largely underestimated and the aim of this review is to highlight the role of TCSs and additional regulatory genes in the direct or indirect regulation of toxin production in $C$. botulinum.

\section{II) Toxinogenesis in C. botulinum, a highly regulated process}

a. Genetic organization of the botulinum toxin locus

In cultures, food, or digestive tract, BoNTs are produced in combination with associated non-toxic proteins (ANTPs) to form complexes of different sizes that spontaneously associate at low $\mathrm{pH}$ and dissociate at $\mathrm{pH} 7.5$ and above (reviewed in[10]). ANTPs include the non-toxic non-hemagglutinin (NTNH) protein and hemagglutinin proteins (HAs) or OrfX proteins whose function is not well defined [11-13]. NTNH has a main role in BoNT protection against low $\mathrm{pH}$ and protease degradation [11]. Thus BoNT complexes are stable in the highly acidic environment of the stomach.

Genes encoding BoNTs and ANTPs are closely clustered together on the botulinum toxin locus (Fig 1), which is organized into two polycistronic operons. The ntnh-bont operon of the botulinum toxin locus is well conserved among BoNT-producing clostridia and consists of the ntnh gene, which codes for the NTNH protein, and immediately downstream, a bont gene (approximately $3.8 \mathrm{~kb}$ ). The gene composition of the second operon varies from type to type. This operon lies upstream of the ntnh-bont operon and is transcribed in the opposite direction. Indeed, the operon can be formed by ha genes ( $h a 70$, hal7, and ha33 also named hal, ha2 and ha3 respectively), which code for HAs proteins and are associated with BoNT/A5, B, C, $\mathrm{D}$ and $\mathrm{G}$ types, or $\operatorname{orfX}$ genes (orfX1, orfX2 and $\operatorname{orfX3)}$ associated with BoNT/A2, A3, A4, E, F types. BoNT/A1 is either associated with HAs or OrfX according to the strains [14-18]. 
Two additional genes (botR and $p 47$ ) are also found in the botulinum toxin locus. botR codes for an alternative sigma factor which plays an important role in the positive regulation of botulinum toxin synthesis (see part IIc). In most trains, botR lies between the two operons, except in botulinum toxin locus type $\mathrm{C}$ and $\mathrm{D}$ where botR is located upstream of ha operon (Fig.1). The function of $p 47$ is still unknown [19]. Most of the strains contain either botR or $p 47$ in their botulinum toxin locus. However, some strains encompass both bot $R$ and $p 47$ which are transcribed in the opposite orientation [14,25-30]. This is the case for strains of the C. botulinum A and F with an orfX-bont locus [20].

Depending on the strain, the ntnh-bont operon can be transcribed as a monocistronic or bicistronic messenger in C. botulinum type A and type $\mathrm{C} 1$ strains, whereas the p47-ntnh-bont operon of botulinum toxin locus of Kyoto F type A2 strain is transcribed as a tricistronic operon only [15,21,22]. The culture conditions can influence the transcription of the botulinum toxin locus genes. For example, in C. botulinum E strain CB11/1-1, distinct expression patterns of the six genes of the botulinum toxin locus at low and high temperatures suggest that type E neurotoxin cluster genes are transcribed as two tricistronic operons at $30^{\circ} \mathrm{C}$, whereas the locus genes are mainly transcribed as monocistronic operon (bontE or $\operatorname{orf} x 1$ alone) and bicistronic (ntnh-p47 and $\operatorname{orf} x 2-\operatorname{orf} x 3)$ at $10^{\circ} \mathrm{C}$ [23]. Transcriptional analysis of $C$. botulinum type A, B and subtype A2 showed that $h a$ and orf $X$ loci are transcribed as tricistronic messengers $[14,16,19,24]$.

\section{b. Expression and kinetic production of botulinum complex}

Expression of botulinum toxin locus genes is a highly controlled process involving various environmental and regulatory factors. Indeed, botulinum toxin gene expression during growth was monitored using real-time PCR and northern blot analyses on C. botulinum type $\mathrm{A}$ and $\mathrm{E}[21,32-34]$. At $37^{\circ} \mathrm{C}$, the botulinum toxin locus genes exhibit the same kinetics of expression including: weak expression during the exponential growth phase, then an increased expression reaching its maximal rate (100-fold increase) at the transition phase between the end of the exponential growth and the beginning of stationary phase. After 24-h of growth, the expression rate of botulinum toxin locus genes returns to the rate observed in the early growth phase [21,32]. These data suggest that toxin gene expression in C. botulinum is tightly regulated and is growth phase dependent. BoNT and ANTP accumulation in the supernatant of $C$. botulinum type A and E, as monitored by the lethal activity and biochemical approach, reaches the highest value 12 hours after the peak of bont gene expression and remains stable for at least 5 additional days [32]. 
It is not yet defined how the toxin is released in the extracellular medium. One hypothesis suggests that the toxin is freed into the extracellular medium during autolysis. Indeed, comparison of 2 strains from the group I proteolytic stains of C.botulinum type A, Hall A and NCTC2916 (A(B)), shows that they exhibit different patterns of growth, toxin expression, production and toxin release $[35,36]$. Although both strains reach the same maximal amount of toxin after $48 \mathrm{~h}$ of growth in the extracellular medium, neurotoxin release starts during exponential growth and only a small increase in toxin release is observed during autolysis of C. botulinum Hall A, whereas BoNT release and autolysis are concomitant in NCTC916 [35]. However, the same strains show similar growth kinetics and patterns of botulinum locus gene expression and BoNT accumulation in the extracellular medium in another study using different culture media [32]. Moreover, BoNT/A release in the extracellular medium starts concomitantly with the exponential growth phase as monitored by ELISA assay and lethality test on mice suggesting that another process than autolysis is involved [32,33]. Thus, the release of BoNT/A in the extracellular medium may differ depending on experimental procedure, growth medium and strains.

Interestingly, $\mathrm{C} 2$ toxin produced by type $\mathrm{C}$ and $\mathrm{D}$ strains, which is an additional toxin distinct from the neurotoxin, is only produced during the sporulation phase. Conversely, no direct link between BoNT synthesis and sporulation has been identified at least in $C$. botulinum A and E.. [21,32,35]. However, A significant difference in antp expression was observed between the two conditions. Thereby, a study performed in our laboratory showed that in non-sporulating cultures of C. boutlinum NCTC2916, the relative expression of bont/A and antps are equivalent, while in sporulating conditions, the relative expression of bont/A is twofold higher than that of $n t n h / A$ and ha35. Moreover, in sporulating conditions, $h a$ genes are differentially expressed with ha35 transcripts being twofold more expressed than hal7 and ha70 transcripts [32]. Thus an indirect link between sporulation and BoNT/ANTP production may exist.

c. BotR, an alternative sigma factor

Before 2012, the only known regulator of toxinogenesis in C. botulinum was the alternative sigma factor BotR that drives RNA polymerase to transcribe genes of both operons of the botulinum toxin locus [37]. The DNA binding properties of BotR were first described in 1995 in C.botulinum type C [15]. Homologs of BotR were subsequently identified in $C$. botulinum types A, B, D, F and G but no homologs could be found in C. botulinum type E. Homologs of BotR have also been evidenced in other Clostridium species like TetR in 
Clostridium tetani, TcdR in Clostridium difficile, and UviA in Clostridium perfringens [19,38-40]. These homologs are positive regulators of their corresponding toxin genes (TetR for tetanus toxin gene (tent), TcdR for tox $A$ and tox $B$ and UviA for $C$. perfringens bacteriocin gene), and they are functionally interchangeable in vitro and in vivo [41]. For example, an overexpression of botR/A and to a lesser extent botR/C in C. tetani, enhances TeNT synthesis suggesting that these sigma factors have a conserved function in several Clostridium and that they probably have evolved from a common ancestor [40]. BotR/A and its homologs have been assigned to a new TcdR sub-family group within the sigma (70) family on the basis of target DNA sequence (Fig.2) [34]. $\square$ Indeed the members of the TcdR subfamily recognize a conserved promoter region (TTTAXA) which is distinct from the motifs targeted by the sigma factors from other families [42] $\square$. Moreover, the fact that TcdR is not interchangeable by a group 4 ECF (Bacillus subtilis $\sigma \mathrm{w}$ ), a close related $\square \square \square \square \square$ factor group, $\square$ further supports that TcdR and related proteins belong to a distinct group of $\square \square \square \square \square$ factors $\square$ [42].

The mechanism of action of BotR/A and TetR was exhaustively studied by S. Raffestin et al. [19]. Footprinting experiments on DNA fragments containing the promoter region of the ntnh-bont/A operon showed that BotR/A specifically recognizes conserved sequences localized at -10 (GTTATA), and -35 (TTACA) within the promoter binding sites ATGTTATATataa and TagGTTTACAAAA, respectively [19]. These regions are also conserved in the promoter region of $h a$ operon of $C$. botulinum types B, C, D and G and in the promoter of tent in C. tetani [19]. Then, BotR promotes the RNA polymerase-dependent transcription of the ntnh-bont and ha operons. Overall, BotR/A positively regulates the operons of the botulinum toxin locus in a dose dependent manner, increasing production of BoNT and ANTPs, and it was concluded that BotR/A is a transcriptional activator of botulinum toxin locus genes [40]. BotR/A can also target its own promoter, but no initiation of transcription could be observed in vitro, whereas TcdR in C. difficile activates its own expression $[19,43]$.

In comparison with bont/A expression, botR/A is expressed approximately 100 fold less than the other genes of the botulinum toxin locus [32,33]. Although BotR directly regulates botulinum toxin locus genes, it seems to have multiple targets. Transcriptomic analysis in $C$. botulinum A were performed in isogenic strains which either overexpressed or partially repressed botR/A [40]. In these strains, a set of genes are overexpressed (15) and underexpressed (6) of at least 4-fold compared to the wild type strain including botulinum toxin locus genes but also many enzyme genes and to a lower extent, membrane and transporter genes (unpublished data as monitored by a microarray based transcriptomic 
analysis [44]). However, it is highly improbable that BotR is the only regulatory factor involved in toxinogenesis of $C$. botulinum. Indeed, expression of botulinum toxin genes and toxin production in $C$. botulinum $\mathrm{E}$, which lacks botR but has $p 47$, show the same kinetics of growth and toxin production as in $C$. botulinum A [32]. The maximal expression of bont/E at the transition between the late exponential and early stationary phases strongly suggests that other regulatory pathways are involved.

\section{d. Environmental stimuli in BoNT production and complex stability}

It has been known for decades that nutrient availability and environmental stimuli play an important role in toxin production in C. botulinum (Fig.3).

The source of nitrogen in culture media is critical for BoNT production. Although toxin production by various $C$. botulinum strains has been obtained in diverse culture media ranging from complex media containing meat, yeast hydrolysates, vegetable extracts, to simpler media based on hydrolysates of casein, the complex media with meat extracts yielded the highest levels of toxin [45]. It seems that the size of peptides in complex media is critical (unpublished data).

Certain amino acids have been found to be important for toxin synthesis. For example, in minimal defined medium, group I $C$. botulinum strains require high concentrations of phenylalanine (>1 g/l) and arginine (>3 g/l) for maximal toxin production [46]. However, in C. botulinum Okra B and Hall A, an excess of arginine in the culture media (20g/l) represses BoNT/A and BoNT/B synthesis, respectively, without modification of growth or lysis [46]. A similar phenomenon is observed with proline, glutamate or ammonia. Moreover, tryptophan in culture media partially represses neurotoxin production in several $C$. botulinum type $\mathrm{E}$ strains without modifying growth kinetics, but this effect seems to be strain dependent [47]. Rapidly metabolizable sugars such as glucose are not absolutely required for neurotoxin synthesis but enhance C.botulinum growth and subsequently promote increased toxin production [48]. Therefore, rapidly metabolizable sugars are essential factors for maximal toxin production.

The control of BoNT synthesis by the general metabolism is probably mediated, at least partially by CodY, which is a global regulator that governs the transition from the exponential growth to stationary phase. CodY senses the level of GTP and controls the expression of numerous genes (>100 in Bacillus subtilis) [49]. In C. botulinum A, CodY has been reported to regulate positively the expression of bont by interacting with the promoter of the ntnh-bont operon on a site distinct from that recognized by BotR/A in a GTP-dependent manner [50]. 
Various environmental stimuli such as carbon dioxide, $\mathrm{NaCl}$ concentration, $\mathrm{pH}$ and

240

241

242

243

244

245 temperature have also been shown to regulate botulinum toxin production. $\mathrm{CO}_{2}$, which is commonly used in food preservation, has a strong antimicrobial activity on aerobic bacteria but is metabolized by numerous anaerobic bacteria and enhances toxin production in many bacteria such as Staphylococcus aureus, Vibrio cholerae or Bacillus anthracis [51-53]. In non-proteolytic $C$. botulinum type $\mathrm{B}$ and $\mathrm{E}$ strains from group II, $\mathrm{CO}_{2}$ enhances toxin production but has only minimal effects in C. botulinum type A strains [54-56]. An increased $\mathrm{CO}_{2}$ concentration from $10 \%$ to $70 \%$ leads to a more than 5-fold increase in BoNT/B neurotoxin synthesis without any growth modification. In C. botulinum type E, the increased $\mathrm{CO}_{2}$ concentration (70\%) also enhances toxin production despite a growth rate reduction [54]. Thus, in $C$. botulinum type E, toxin production seems to be linked to growth rate as it has been described in stress situations in C. difficile [34].

Li et al. have investigated the effects of $\mathrm{pH}$ on $C$. botulinum type A growth, toxin gene expression and production [57]. BoNT/A gene expression is optimal at $\mathrm{pH} 7$ and then decreases at lower or higher $\mathrm{pH}$. Thus, $\mathrm{pH}$ is a critical parameter controlling bont/A expression and subsequent toxin synthesis and is of great importance in safety of food processing.

High temperature (at least until $44^{\circ} \mathrm{C}$ ) which is a common signal involved in the relay of alternative sigma factors (reviewed in [58]), seems not to be an inhibitory signal for toxin production in C. botulinum type $\mathrm{E}$ and $\mathrm{A}$, but appears to play an important role in complex stability [32]. Even though botulinum toxin locus genes are expressed at the same level between $37^{\circ} \mathrm{C}$ and $44^{\circ} \mathrm{C}$, BoNT/A activity monitored by its lethal activity on mice is strongly reduced after $24-48 \mathrm{~h}$ of culture incubated at $44^{\circ} \mathrm{C}$ suggesting that a protease leading to BoNT/A degradation is activated at $44^{\circ} \mathrm{C}$ in $C$. botulinum Hall A strain. Indeed, a $\mathrm{Ca}^{++}$ dependent protease activated at high temperature is produced by $C$. botulinum A. Unlike $C$. botulinum type A, cultures at $44^{\circ} \mathrm{C}$ has no effect on lethal activity levels of $C$. botulinum type E strains which are not proteolytic bacteria [32]. It has been known for decades that bacterial growth adaptation to changes in temperature implicates two types of protein, those that are induced by cold called Cold Shock Proteins (CspA, CspB, and CspC) and those induced by heat, called Heat Shock Protein (HSPs) [59,60]. Homologs of CspB and HSPs have been identified in $C$. botulinum type A and D to play a major role in temperature tolerance and stressful environmental conditions [61-63]. It is not known whether these proteins also control the toxin synthesis or they play a role in toxin protection. 
Thus, the composition of culture media and culture conditions differentially affects BoNT synthesis depending on $C$. botulinum strains and one of the major challenges in the understanding of the toxinogenesis in C. botulinum, is to identify the molecular mechanisms associated with these environmental regulators.

\section{III) TCSs play a central role in the regulation of toxinogenesis in $C$. botulinum}

Thousands of TCSs have been identified among all kingdoms, in Gram-positive, Gram-negative bacteria, Archaea, and to a lesser extent in eukaryotic organisms. TCSs are implicated in the control of various physiological processes including osmoregulation (for example OmpR/EnvZ in E. coli), and sporulation (KinA/ KinB/ KinC and Spo0F/ Spo0B/ Spo0A in B. subtilis), but also in cell-cell communication, and control of virulence factor production [64-68].

The number of TCSs can vary from none in Mycoplasma genitalium to 80 in Synochocystis species, which represents $2.5 \%$ of the entire Synochocystis genome [69,70]. Among these TCSs, several are implicated in the regulation of virulence factors in Grampositive and Gram-negative bacteria such as Staphylococcus aureus, Salmonella thyphimurium, S. enterica, and Bordetella. pertussis [71-74]. However, due to their pleiotropic functions and inteconnexions, the individual role played by TCS in toxinogenesis is still unclear and it's highly probable that toxin synthesis is under the control of a complex regulatory network including TCSs and also sigma factors, orphan regulators and/or small regulatory RNAs.

a. Biochemistry and interconnexions of TCSs

TCSs are transduction signal phosphorelay systems that require ATP and at least 2 proteins: one transmembrane protein which detects the environmental changes called sensor histidine kinase (SHK) and a regulatory protein (RR for response regulator) which is typically a DNA binding protein (Fig.4). The two TCS genes are often expressed from a single operon which can autoregulate itself [75].

The signal pathway is triggered by the SHK protein, which senses the stimuli by its Nterminal region and autophosphorylates a conserved histidine $(\mathrm{H})$ residue localized in the $\mathrm{C}$ terminal region at the expense of ATP. SHKs are structurally complex, homodimeric integral membrane proteins which can vary in size from $40 \mathrm{kDa}$ to $200 \mathrm{kDa}$. Each protomer is divided into several functionally and structurally dissociable domains: one sensor, two transmembrane helices called linker domains, and one HAMP domain (histidine kinase, adenylyl cyclase, 
306

307

308

309

310

311

312

313

314

315

316

317

318

319

320

321

322

323

324

325

326

327

328

329

330

331

332

333

334

335

336

337

338

methyl accepting chemotaxis protein and phosphatase). The HAMP domain connects the second transmembrane domain to the dimerization and histidine phosphorylation domain (DH) where the conserved $\mathrm{H}$ is localized, and finally to a catalytic and ATP-binding domain (CA) (reviewed in [76]). The sensor domain can be highly variable, allowing the detection of a wide range of stimuli. SHKs can sense environmental stimuli when bound to the periplasmic membrane like EnvZ which is involved in the osmoregualtion pathway in E. coli. But SHKs can also detect intracellular stimuli through enzymatic behavior (for example CheA involved in the control of chemotaxis in E. coli) or by interacting with other cytoplasmic protein which promote an adaptive response (reviewed in [77]). Some SHKs exist as hybrids that contain multiple phosphodonor and phosphoacceptor sites, adding steps to the phosphorelay system as in the case of BarA which is implicated in growth stationary phase and ArcB which is involved in the anoxic redox control [69].

Once SHK is phosphorylated, the phosphate group is transferred to a conserved aspartate residue (D) on the cognate RR receptor domain which regulates the expression of specific target genes. RR proteins are structurally less complex than SHKs but their multitude of targets make them difficult to classify [78]. They are divided into one receiver domain (REC) which is well conserved among RRs and one variable effector output domain [79]. RR proteins catalyze phosphate group transfer from SHK H to the conserved aspartate (D) residue on the receiver domain of RR protein, and then to the effector output domain. Most of the RRs can also catalyze autodephosphorylation to limit the time lapse of activation. The effector domains are variable. They are either DNA-binding, RNA-binding, ligand binding, transporter output domain or core enzyme and can act at a transcriptional post-transcriptional or post-translational level. However most of them are DNA-binding proteins and are transcriptional regulators. They contain only one output domain as in the case of LytR/AgrA, OmpR/PhoB and Spo0A domain families or two output domains as in the case of Ntrc/DctD family (reviewed in $[76,77,80])$.

SHKs and RRs share sequence and structural similarities permitting cross-phosphorylation or cross-communication between them. As for RRs, most SHKs are bifunctional and can catalyze phosphorylation and dephosphorylation of their cognate RR. Since RRs are more abundant than SHKs, SHK phosphorylation is competitive depending on their interaction with RRs. Three types of cross-communication have been described: cross-talk, cross-regulation and one-to-many or many-to-one interaction. However in most cases, the cross-talks have only been described after important genetic modifications like overexpression of SHKs (see 
339

340

341

342

343

344

345

346

347

348

349

350

351

352

353

354

355

356

357

358

359

360

361

362

363

364

365

366

367

368

369

370

371

372

[81]). These data highlight the fact that TCSs should not be studied individually, but in interaction with other TCSs and bacterial regulatory systems.

b. TCSs in C. botulinum

In 2007, the first genome of C. botulinum Hall A was sequenced and its analysis allowed the prediction of the presence of several regulatory systems including 15 sigma factors, 16 orphan genes and 28 putative TCSs [82]. Another analysis showed that this genome contains 39 proteins which exhibit TCS characteristics including a Rec domain and a DNA binding domain [33].

Analysis of RRs show that numerous C. botulinum Hall A TCSs share more than $60 \%$ identity with homologs in other clostridia [33]. Among the 39 C. botulinum Hall A TCSs, the majority (12/39) are homologous to those found in C. carboxidivorans and C. ljungdahlii. Eight RRs also exhibit high TCS similarity to the closely related C. tetani RRs. However, some RRs (12) have no similarity with proteins in other clostridia and thus seem specific of $C$. botulinum. Interestingly, 2 RRs, of which one is an apparent orphan regulator, show high protein identity (38\%) with the VirR protein of the well-known VirR-VirS C. perfringens TCS. The VirR-VirS TCS regulates the synthesis of numerous toxins in $C$. perfringens at the transcriptional level, either directly by interacting with the toxin gene promoter like in the case of theta toxin or perfringolysin $\mathrm{O}$, or indirectly via a regulatory RNA (VR-RNA) like in the case of alpha toxin and collagenase A [83-85]. However, the VirR-VirS related TCS in $C$. botulinum Hall A seems not to be involved in the regulation of toxinogenesis (see below)

Two-third of TCS RR proteins identified in C. botulinum Hall A by genome analysis belong to the OmpR family. Regulator proteins of the OmpR family have been described to control multiple functions including bacterial surface organization, polysaccharide synthesis and/or assembly. One of the best understood TCSs is OmpR/EnvZ. In E. coli, OmpR/EnvZ TCS is involved in the adaptive response to extracellular osmolarity changes by regulating the transcription rate of 2 porin proteins. Moreover, it has also been demonstrated that regulation by the OmpR/EnvZ TCS is critical for curli formation and thus plays an important role in biofilm formation [86].

Four C. botulinum RRs belongs to the LytR family, which is widespread among bacteria and control the synthesis of several virulence factors. The LytR family has been characterized in $S$. aureus. Indeed, the $S$. aureus infection potency is linked to the synthesis of more than 50 virulence factors including toxins which are mostly regulated by cellular density (quorum sensing) via the accessory gene regulator (Agr) system including the TCS AgrA/LytR 
373

374

375

$[80,87,88]$. Other $C$. botulinum predicted TCSs have RRs that belong to the NarL family (2/39) which regulates nitrite- and nitrate-dependent gene expression or CheB (1/39) for chemotaxis in E. coli, and WspR (1/39) which has been found to stimulate biofilm formation in Pseudomonas aeruginosa or Pas_4 (1/39) [33].

\section{c. TCSs and BoNTs production}

Different techniques are available to investigate the regulatory pathway linked to a TCS. One approach is to modulate an environmental signal already known to trigger the TCS of interest by either supplementing or depleting the culture media with this specific signal (nutrient or chemical compounds). However, TCSs function as a saturating process leading to variable results depending on the amplitude of the environmental signal variation, as is the case of the phosphate regulon [89]. Another way is to modulate the TCS expression in bacteria at the transcriptional or translational level. As discussed above, SHK domain overexpression may lead to cross-talk, rendering the involvement of one TCS in a pathway of interest difficult to analyze (see [81]). In contrast, silencing or knocking out TCS gene expression can be a relevant experiment to identify the role of a TCS [33,90-92].

The potential role in toxin production of 34 TCSs has been investigated in the laboratory using the antisense mRNA strategy. Compared to gene knock-outs, the mRNA antisense methodology only partially silences gene expression but allows the detection of very fine regulation. The ability of isogenic $C$. botulinum strains to produce BoNTs and ANTPs was investigated by western blot analysis and ELISA assay in the culture supernatant, and the botulinum locus gene expression by qRT-PCR [37]. This method allowed the identification of 6 TCSs involved in toxinogenesis in C. botulinum Hall A [33,92].

Isogenic strains repressed in 5 RRs showed a drastic decrease in toxin and ANTP production, with, for some strains, a more important decrease than that observed in the isogenic strain repressed in botR/A. However, 2 of these isogenic antisense strains corresponding to CLC_0411 and CLC_3293 TCSs present a more rapid growth and lysis explained by drastic changes in cell wall or surface structure [33]. The corresponding RRs belong to the OmpR family and thus seem to be involved in the regulation of cell surface properties, e.g. surface polysaccharide synthesis and integrity and only indirectly in toxin production and/or secretion. Isogenic strains of the 2 RRs sharing sequence similarity with VirS/ VirR RR were also obtained. The corresponding orphan RR (CLC_0632) showed a drastic delay in growth compared to the wild type strain but produces a similar level of toxin. Thus, this TCS seems to be involved in global metabolism and not in the direct control of toxin synthesis. In this case, the other homolog (CLC_1105) of VirR did not show any 
407

408

409

410

411

412

413

414

415

416

417

418

419

420

421

422

423

424

425

426

427

428

429

430

431

432

433

434

435

436

437

438

439

440

difference in growth or toxin production. Thus VirR/VirS TCS homologs seem to regulate different processes in $C$. perfringens and in C. botulinum [33]. Concerning the three other positive regulatory TCSs (CLC_1093/CLC_1094, CLC_1914/CLC_1913 and CLC_0661/CLC_0663) no difference in growth or lysis was observed in the isogenic strains containing antisense mRNA construction targeting each of these three TCS RRs. Expression of bont/A and antps in isogenic strains containing antisense mRNA construction targeting the 3 TCSs is repressed at the same level as in the isogenic antisense strain repressed for botR/A. But the production of BoNT/A and ANTPs is slightly lower than in the control strain, indicating that these three TCSs may have a more important effect on toxin production than BotR/A. Moreover qRT-PCR analysis showed no decrease in botR/A expression in these isogenic strains, indicating that the three TCSs control directly or indirectly the expression of the botulinum locus genes independently of BotR/A [33].

The first TCS downregulating BoNT synthesis was described recently [92]. In this study, the methodology used is a shutdown of TCS gene of interest by the Clostron technology which is a group II intron-based insertional mutagenesis [93]. Unlike the mRNA antisense method, Clostron engineering totally represses gene expression. The TCS CBO0787/CBO0786, equivalent to CLC_0842/CLC_0843 is located approximately $11 \mathrm{~kb}$ upstream of the botulinum toxin locus in contrast to the other TCSs involved in positive regulation of bont which lie at distance of the botulinum. This TCS binds to the consensus core promoter region of both operons of the botulinum toxin locus, thus inhibiting the transcription of the botulinum locus genes enhanced by BotR/A. Thus, this TCS probably acts by preventing BotR/A binding to the promoters of the botulinum toxin locus operons and thus inhibiting the transcription of botulinum toxin locus genes. Additionally, TCS CBO0787/CBO0786 could be also an anti-sigma factor similarly to TcdC in $C$. difficile by impairing the transcription and/ or translation of $\operatorname{bot} R / A$. But, this TCS has not been found to bind to botR/A promoter [94]. Isogenic strain silenced for TCS CBO0787/ 0786 by the mRNA antisense method has been investigated [33]. No difference in growth or toxin production compared to wild type strain was evidenced suggesting that the regulation of toxin synthesis by this TCS is not a tight process.

Interestingly, the five TCSs which directly or indirectly control positively BoNT production are conserved among $C$. botulinum strains from group I (subtype A1, A(B), A2, A3, Ba4, B1 and F) but they are not detected in C. botulinum group II strains. Similarly, the negative regulator TCS has homologs (more than $90 \%$ identity) in other C. botulinum group I strains including subtypes (A2 strain Kyoto, A5 and F strain Langeland) [33,92]. No 
significantly related genes were found in other $C$. botulinum groups. These data strongly suggest that $C$. botulinum from group I share a common regulatory network of toxin production distinct from that of the other C. botulinum groups.

Overall, certain TCSs control toxin production either in a direct way by regulating botulinum locus gene transcription or indirectly via regulating general metabolism pathways.

d. Quorum sensing, TCS and toxin production

One of the most interesting systems that bacteria have developed to adapt their physiological behaviors and pathogenesis (biofilm formation, virulence, antibiotic resistance) to local population density is quorum sensing. Quorum sensing controls multiple metabolic processes but also virulence factors in several Gram-positive and Gram-negative bacteria. For example, it has been shown that quorum sensing is implicated in the production of the type III secretion system and the regulation of motility and flagella in $E$. coli EHEC (enterohemorrhagic E. coli) and EPEC (enteropathogenic E. coli), or in the production of virulence factors in V. cholerae and biofilm formation in C. perfringens or P. aeruginosa [9597]. Thus quorum sensing may be a potential antimicrobial target.

For decades, several teams have been trying to evidence quorum sensing in C. botulinum. It was shown in $C$. botulinum 56A that spores in contact with latency phase bacteria germinate more rapidly than the control spores [98] demonstrating that quorum sensing in $C$. botulinum exists and may influence spore germination.

Quorum sensing molecular mechanisms differ between Gram-positive and Gramnegative bacteria. In the case of Gram-negative bacteria, the stimuli are small molecules called AutoInducers (AIs) that are passively transported through the bacterial cell wall, whereas in Gram-positive bacteria, the AIs are secreted by specific transport systems and detected by TCSs (Fig. 5).

One well known peptide detected by this system is AI-2 (AutoInducer-2) produced by LuxS from SAM (S-adenosylmethionine). Numerous bacterial species carry luxS in their genomes and thus AI-2 can be produced and detected by different species allowing interspecies communication [99]. In order to determine the involvement of LuxS in toxinogenesis, an isogenic strain silenced for the homologs of luxS identified in the genome of $C$. botulinum Hall A was generated, but only a small delay in growth and toxin production could be observed (unpublished data). Even though the implication of LuxS in the C. botulinum toxinogenesis is still unclear, it has been demonstrated that the TCS VirR/VirS of $C$. perfringens has a pleiotropic action and regulates toxin production but also luxS transcription. LuxS enhances toxin production in the mid-exponential growth phase, demonstrating that 
475

476

477

478

479

480

481

482

483

484

485

486

487

488

489

490

491

492

493

494

495

496

497

498

499

500

501

502

503

504

505

506

507

508

TCS and quorum sensing are tightly linked in maximal toxin production in $C$. perfringens [83,100]. Furthermore, AI-2 positively regulates virulence factors in C. difficile such as toxin $\mathrm{A}$ and $\mathrm{B}$, and also the holine encoded by $t c d E$ which plays an important role in biofilm formation [101-103].

Another type of AIs is the AIPs (AutoInducers Peptide). AIPs are small peptides that require a highly specific detection by appropriate TCSs and that only mediate intra-species communication [104] (Fig. 5). One of the most well known systems of intra-species communication is the Agr system of S. aureus which is responsible for $50 \%$ of iatrogenic infection. In this system the AIP is produced from a peptide encoded by $\operatorname{agr} D$ which is then hydrolyzed by AgrB, an integral membrane endopeptidase. Once AIP reaches a threshold level in the environment, it is detected by the TCS AgrA/ AgrC which upregulates the production of a small RNA (sRNA) called ARN III and subsequently enhances toxin production [105]. A putative agr BD signaling system has been identified in proteolytic $C$. botulinum group I strains and homologs of $\operatorname{agrB}$ and $\operatorname{agrD}$ called $\operatorname{agr} r$-1 and $a g r-2$ were identified but they seem to play different roles than in $S$. aureus. Indeed, agr-1 is suggested to regulate the sporulation state while agr-2 seems to be implicated in BoNT/A production [106]. However the isogenic antisense strain silenced for the homologous AgrA/ AgrC TCS in C. botulinum Hall A was not impaired in BoNT production or growth in the tested experimental process [33]. Thus the effect and the mode of action of agr-2 homologs in toxin production in $C$. botulinum remain to be characterized.

In addition, quorum sensing plays a major role in the transition between growth phase and stationary phase and regulates virulence factor production at high cellular density. This is the case in $P$. aeruginosa, which is a major opportunistic pathogen responsible for pulmonary infections as well as burn wound and other infection. Its multiple virulence factors are expressed at high cellular density and are under the control of quorum sensing (reviewed in [107]). Thus quorum sensing is evidenced only under certain conditions, such as growth in nutrient-limitation, very high population density, or in response to specific stresses and it is conceivable that the experimental conditions used in $C$. botulinum studies are not appropriate to evidence a quorum sensing-mediated regulation in this bacterium.

\section{IV) Discussion and conclusion}

Data collected in recent decades has shown that TCSs are highly involved in several processes in bacteria including the regulation of virulence factor production such as toxins. However, few links have been made between environmental stimuli and bacterial processes, 
509

510

511

512

513

514

515

516

517

518

519

520

521

522

523

524

525

526

527

528

529

530

531

532

533

534

535

536

537

538

539

540

underestimating the capacity of bacteria to adapt to their environment. Thanks to the structural understanding of TCSs, the mode of action of TCSs is well understood, but a correlation between SHK domain and stimuli is still elusive. Even though techniques based on phenotypic microarray approaches are available to characterize phenotypes under different environmental conditions, the number and combination of variable parameters are too numerous and complex to effectively carry out a systematic screening of all stimuli and all putative genes [108].

As discussed above, only a few regulatory systems are known to participate in botulinum toxin production in $C$. botulinum. The alternative sigma factor BotR was the first positive regulator identified in this process. Botulinum locus genes reach their maximum expression at the transition phase between exponential and stationary growth $[21,32]$. The transition between these 2 phases is a highly regulated process in E. coli and is under the control of RpoS, a sigma factor which replaces the vegetative sigma factor $\sigma 70$ in stationary phase and under numerous stress conditions (reviewed in [109]). This mechanism is very complex and is partly regulated by a TCS (BarA/ UvrY). Even if no TCS has been described to regulate the transcription of BotR, botR/A has the same kinetic of expression as the other genes of the botulinum toxin locus suggesting that botR/A regulation of expression is under the control of environmental stimuli [32].

Small RNAs (sRNAs) are another regulatory system described to be involved in the regulation of virulence factor production in bacteria and in quorum sensing (reviewed in [110]). Numerous sRNAs have been identified in the genomes of 21 Clostridium species and most of them are not found in bacteria of other phyla [111]. Although the synthesis of toxins in $C$. perfringens is under the control of a TCS and involves a sRNA called VR-RNA, the role of sRNAs in botulinum toxin synthesis is still unknown [83].

Overall, only a few regulatory systems of toxinogenesis are described in C. botulinum including the positive regulatory sigma factor BoTR and 6 TCSs $[33,40,92]$. Some small regulatory RNAs may also be involved but no such regulation has yet been described [111]. The environmental factors triggering BoNTs synthesis are so far poorly understood but new technologies associated with a better understanding of the structural and molecular mechanism of TCSs should help to unravel the mechanism of toxin regulation and eventually lead to the development of new strategies to control botulism. Due to their absence in mammals and their wide range of action, TCSs constitute interesting therapeutic targets. 
542

543

544

545 


\section{References}

547 [1] Gill DM. Bacterial toxins: a table of lethal amounts. Microbiol Rev 1982;46:86-94.

[2] Louis DS. Smith P. and HS. Botulism: The Organism, Its toxin, The disease. Second edi. 1988.

[3] Marvaud J-C, Raffestin S, Popoff MR. Le botulisme : agent, mode d'action des neurotoxines botuliques, formes d'acquisition, traitement et prévention. C R Biol 2002;325:863-78.

[4] Smith T, Lou J, Geren I. Sequence Variation within Botulinum Neurotoxin Serotypes Impacts Antibody Binding and Neutralization. Infect Immun 2005.

[5] Dover N, Barash JR, Hill KK, Xie G, Arnon SS. Molecular Characterization of a Novel Botulinum Neurotoxin Type H Gene. J Infect Dis 2013:1-11.

[6] Genigeorgis C. Microbial and safety implications of the use of modified atmospheres to extend the storage life of fresh meat and fish. Int J Food Microbiol 1985;1:237-51.

Mascher G, Derman Y, Kirk DG, Palonen E, Lindström M, Korkeala H. The twocomponent system CLO3403/CLO3404 of Clostridium botulinum E1 Beluga is important for cold-shock response and growth at low temperature. Appl Environ Microbiol 2013.

[8] Lindström M, Dahlsten E, Söderholm H, Selby K, Somervuo P, Heap JT, et al. Involvement of two-component system CBO0366/CBO0365 in the cold shock response and growth of group I (proteolytic) Clostridium botulinum ATCC 3502 at low temperatures. Appl Environ Microbiol 2012;78:5466-70.

[10] Popff MR MJ. Structural and genomic features of clostridial neurotoxins. In: J.E Alouf and J.H. Freer, editor. Compr. Sourceb. Bact. toxin, London Academic press; 1999, p. 174-201.

[11] Gu S, Rumpel S, Zhou J, Strotmeier J, Bigalke H, Perry K, et al. Botulinum neurotoxin

[12] Gu S, Jin R. Assembly and Function of the Botulinum Neurotoxin Progenitor Complex. Microbiol Immunol 2013;364:21-44.

[13] Benefield D a, Dessain SK, Shine N, Ohi MD, Lacy DB. Molecular assembly of botulinum neurotoxin progenitor complexes. Proc Natl Acad Sci U S A 2013:1-6. transcriptional analysis of the type A2 neurotoxin gene cluster in Clostridium botulinum. FEMS Microbiol Lett 2004;235:9-16. 
[15] Hauser D, Gibert M, Marvaud J. Botulinal neurotoxin C1 complex genes, clostridial neurotoxin homology and genetic transfer in Clostridium botulinum. Toxicon 1995;0101:515-26.

[16] Henderson I, Whelan SM, Davis TO, Minton NP. Genetic characterisation of the botulinum toxin complex of Clostridium botulinum strain NCTC 2916. FEMS Microbiol Lett 1996;140:151-8.

[17] Yang GH, Rhee SD, Jung HH, Yang KH. Organization and nucleotide sequence of genes for hemagglutinin components of Clostridium botulinum type B progenitor toxin. Biochem Mol Biol Int 1996;39:1141-6.

[18] Dover N, Barash JR, Hill KK, Davenport KW, Teshima H, Xie G, et al. Clostridium botulinum Strain Af84 Contains Three Neurotoxin Gene Clusters: Bont/A2, bont/F4 and bont/F5. PLoS One 2013;8:e61205.

[19] Raffestin S, Dupuy B, Marvaud JC, Popoff MR. BotR/A and TetR are alternative RNA polymerase sigma factors controlling the expression of the neurotoxin and associated protein genes in Clostridium botulinum type A and Clostridium tetani. Mol Microbiol 2005;55:235-49.

[20] Hill KK, Xie G, Foley BT, Smith TJ, Munk AC, Bruce D, et al. Recombination and insertion events involving the botulinum neurotoxin complex genes in Clostridium botulinum types A, B, E and F and Clostridium butyricum type E strains. BMC Biol 2009;7:66.

[21] Bradshaw M, Dineen SS, Maks ND, Johnson E a. Regulation of neurotoxin complex expression in Clostridium botulinum strains 62A, Hall A-hyper, and NCTC 2916. Anaerobe 2004;10:321-33.

[22] Binz T, Kurazono H, Wille M. The complete sequence of botulinum neurotoxin type A and comparison with other clostridial neurotoxins. J Biol Chem 1990.

[23] Chen Y, Korkeala H, Lindén J, Lindström M. Quantitative real-time reverse transcription-PCR analysis reveals stable and prolonged neurotoxin cluster gene activity in a Clostridium botulinum type E strain at refrigeration temperature. Appl Environ Microbiol 2008;74:6132-7.

[24] Yang G, Rhee S, Jung H, Yang K. Organization and nucleotide sequence of genes for hemagglutinin components of Clostridium botulinum type B progenitor toxin. IUBMB Life 1996;39:1141-6.

[25] Brüggemann H, Wollherr A, Mazuet C, Popoff MR. Genomes of Foodborne and Waterborne Pathogens. In: Liu Y, Kathariou S, Fratamico P, editors., American Society of Microbiology; 2011, p. 185-212.

[26] Collins MD, East a K. Phylogeny and taxonomy of the food-borne pathogen Clostridium botulinum and its neurotoxins. J Appl Microbiol 1998;84:5-17. 
[27] Jacobson MJ, Lin G, Raphael B, Andreadis J, Johnson E a. Analysis of neurotoxin cluster genes in Clostridium botulinum strains producing botulinum neurotoxin serotype A subtypes. Appl Environ Microbiol 2008;74:2778-86.

[28] Kubota T, Yonekura N, Hariya Y, Isogai E, Isogai H, Amano K, et al. Gene arrangement in the upstream region of Clostridium botulinum type $\mathrm{E}$ and Clostridium butyricum BL6340 progenitor toxin genes is different from that of other types. FEMS Microbiol Lett 1998;158:215-21.

[29] Li B, Qian X, Sarkar HK, Singh BR. Molecular characterization of type E Clostridium botulinum and comparison to other types of Clostridium botulinum. Biochim Biophys Acta 1998;1395:21-7.

[30] Lin G, Tepp WH, Pier CL, Jacobson MJ, Johnson E a. Expression of the Clostridium botulinum A2 neurotoxin gene cluster proteins and characterization of the A2 complex. Appl Environ Microbiol 2010;76:40-7.

[31] Hill KK, Smith TJ. Genetic Diversity Within Clostridium botulinum Serotypes, Botulinum Neurotoxin Gene Clusters and Toxin Subtypes 2013;364:1-20.

[32] Couesnon A, Raffestin S, Popoff MR. Expression of botulinum neurotoxins A and E, and associated non-toxin genes, during the transition phase and stability at high temperature: analysis by quantitative reverse transcription-PCR. Microbiology 2006;152:759-70.

[33] Connan C, Brueggemann H, Mazuet C, Raffestin S, Cayet N, Popoff MR. Twocomponent systems are involved in the regulation of botulinum neurotoxin synthesis in Clostridium botulinum type A strain Hall. PLoS One 2012;7:e41848.

[34] Artin I, Carter AT, Holst E, Lövenklev M, Mason DR, Peck MW, et al. Effects of carbon dioxide on neurotoxin gene expression in nonproteolytic Clostridium botulinum Type E. Appl Environ Microbiol 2008;74:2391-7.

[35] Rao S, Starr RL, Morris MG, Lin W-J. Variations in expression and release of botulinum neurotoxin in Clostridium botulinum type A strains. Foodborne Pathog Dis 2007;4:201-7.

[36] Olsen JS, Scholz H, Fillo S, Ramisse V, Lista F, Trømborg AK, et al. Analysis of the genetic distribution among members of Clostridium botulinum group I using a novel multilocus sequence typing (MLST) assay. J Microbiol Methods 2014;96:84-91.

[37] Marvaud JC, Gibert M, Inoue K, Fujinaga Y, Oguma K, Popoff MR. botR/A is a positive regulator of botulinum neurotoxin and associated non-toxin protein genes in Clostridium botulinum A. Mol Microbiol 1998;29:1009-18.

[38] Mani N, Dupuy B. Regulation of toxin synthesis in Clostridium difficile by an alternative RNA polymerase sigma factor. Proc Natl Acad Sci U S A 2001;98:5844-9.

[39] Dupuy B, Mani N, Katayama S, Sonenshein AL. Transcription activation of a UVinducible Clostridium perfringens bacteriocin gene by a novel sigma factor. Mol Microbiol 2005;55:1196-206. 
657

658

[40] Marvaud JC, Eisel U, Binz T, Niemann H, Popoff MR. TetR is a positive regulator of the tetanus toxin gene in Clostridium tetani and is homologous to botR. Infect Immun 1998;66:5698-702.

[41] Dupuy B, Matamouros S. Regulation of toxin and bacteriocin synthesis in Clostridium species by a new subgroup of RNA polymerase sigma-factors. Res Microbiol 2006;157:201-5.

[42] Dupuy B, Raffestin S, Matamouros S, Mani N, Popoff MR, Sonenshein AL. Regulation of toxin and bacteriocin gene expression in Clostridium by interchangeable RNA polymerase sigma factors. Mol Microbiol 2006;60:1044-57.

[43] Mani N, Lyras D, Barroso L. Environmental response and autoregulation of Clostridium difficile TxeR, a sigma factor for toxin gene expression. J Bacteriol 2002;184:5971-8.

[44] Connan C, Denève C, Mazuet C, Popoff MR. Regulation of toxin synthesis in Clostridium botulinum and Clostridium tetani. Toxicon 2013;75:90-100.

[45] Shone, C.C. and Tranter HS. Growth of Clostridia and preparation of their neurotoxins. Curr Top Microbiol Immunol 1995;195:146-60.

[46] Patterson-Curtis S, Johnson E. Regulation of neurotoxin and protease formation in Clostridium botulinum Okra B and Hall A by arginine. Appl Environ Microbiol 1989;55.

[47] Leyer G, Johnson E. Repression of toxin production by tryptophan in Clostridium botulinum type E. Arch Microbiol 1990:443-7.

[48] Whitmer M, Johnson E. Development of improved defined media for Clostridium botulinum serotypes A, B, and E. Appl Environ Microbiol 1988;54:753-9.

[49] Brinsmade SR, Alexander EL, Livny J, Stettner AI, Segrè D, Rhee KY, et al. Hierarchical expression of genes controlled by the Bacillus subtilis global regulatory protein CodY. Proc Natl Acad Sci U S A 2014;111:8227-32.

[50] Zhang Z, Dahlsten E, Korkeala H, Lindström M. Positive regulation of botulinum neurotoxin gene expression by CodY in Clostridium botulinum ATCC 3502. Appl Environ Microbiol 2014.

[51] Ross R a, Onderdonk a B. Production of toxic shock syndrome toxin 1 by Staphylococcus aureus requires both oxygen and carbon dioxide. Infect Immun 2000;68:5205-9.

[52] Shimamura T, Watanabe S, Sasaki S. Enhancement of enterotoxin production by carbon dioxide in Vibrio cholerae. Infect Immun 1985;49:455-6.

[53] Hoffmaster a R, Koehler TM. The anthrax toxin activator gene atxA is associated with CO2-enhanced non-toxin gene expression in Bacillus anthracis. Infect Immun 1997;65:3091-9. 
[54] Artin I, Mason DR, Pin C, Schelin J, Peck MW, Holst E, et al. Effects of carbon dioxide on growth of proteolytic Clostridium botulinum, its ability to produce neurotoxin, and its transcriptome. Appl Environ Microbiol 2010;76:1168-72.

[55] Lovenklev M, Artin I, Hagberg O, Lo M, Borch E, Holst E, et al. Quantitative interaction effects of carbon dioxide, sodium chloride, and sodium nitrite on neurotoxin gene expression in nonproteolytic Clostridium botulinum type B. Appl 2004;70:292834.

[56] Eisele K-H, Fink K, Vey M, Taylor H V. Studies on the dissociation of botulinum neurotoxin type A complexes. Toxicon 2011;57:555-65.

[57] Li T, Tian R, Cai K, Wang Q, Chen F, Fang H, et al. The Effect of pH on growth of Clostridium botulinum type A and expression of bontA and botR during different growth stages. Foodborne Pathog Dis 2013;10:692-7.

[58] Narberhaus F, Waldminghaus T, Chowdhury S. RNA thermometers. FEMS Microbiol Rev 2006;30:3-16.

[59] Neidhardt F. The genetics and regulation of heat-shock proteins. Annu Rev Genet 1984;18:295-329.

[60] Selby K, Lindström M, Somervuo P, Heap JT, Minton NP, Korkeala H. Important role of class I heat shock genes hrcA and dnaK in the heat shock response and the response to $\mathrm{pH}$ and $\mathrm{NaCl}$ stress of group I Clostridium botulinum strain ATCC 3502. Appl Environ Microbiol 2011;77:2823-30.

[61] Söderholm H, Lindström M, Somervuo P, Heap J, Minton N, Lindén J, et al. cspB encodes a major cold shock protein in Clostridium botulinum ATCC 3502. Int J Food Microbiol 2011;146:23-30.

[62] Selby K, Lindström M, Somervuo P, Heap JT, Minton NP, Korkeala H. Class I heat shock genes hrcA and dnaK play an important role in heat shock response and response to $\mathrm{pH}$ and $\mathrm{NaCl}$ stress of group I Clostridium botulinum ATCC 3502. Appl Environ Microbiol 2011;77:2823-30.

[63] Sagane Y, Hasegawa K, Mutoh S, Kouguchi H, Suzuki T, Sunagawa H, et al. Molecular characterization of GroES and GroEL homologues from Clostridium botulinum. J Protein Chem 2003;22:99-108.

[64] Cai SJ, Inouye M. EnvZ-OmpR interaction and osmoregulation in Escherichia coli. J Biol Chem 2002;277:24155-61.

[65] Parkinson JS. cheA, cheB, and cheC genes of Escherichia coli and their role in chemotaxis. J Bacteriol 1976;126:758-70.

[66] Colloms SD, Alén C, Sherratt DJ. The ArcA/ArcB two-component regulatory system of Escherichia coli is essential for Xer site-specific recombination at psi. Mol Microbiol 1998;28:521-30. 
[67] Grossman AD. Different roles for KinA , KinB , and KinC in the initiation of sporulation in Bacillus subtilis . Different Roles for KinA, KinB , and KinC in the Initiation of Sporulation in Bacillus subtilis 1995;177.

[68] Pernestig A, Georgellis D, Romeo T, Suzuki K, Tomenius H, Normark S. The Escherichia coli BarA-UvrY Two-Component System Is Needed for Efficient Switching between Glycolytic and Gluconeogenic Carbon Sources 2003;185:843-53.

[69] Mizuno T, Kaneko T, Tabata S. Compilation of all genes encoding bacterial twocomponent signal transducers in the genome of the cyanobacterium, Synechocystis sp. strain PCC 6803. DNA Res 1996;414:407-14.

[70] Mizuno T. [His-Asp phosphotransfer signal transduction]. Tanpakushitsu Kakusan Koso 1998;44:412-20.

[71] Miller SI, Kukral a M, Mekalanos JJ. A two-component regulatory system (phoP phoQ) controls Salmonella typhimurium virulence. Proc Natl Acad Sci U S A 1989;86:5054-8.

[72] Yarwood J. Identification of a Novel Two-Component Regulatory System That Acts in Global Regulation of Virulence Factors of Staphylococcus aureus. J Bacteriol 2001.

[73] García-Calderón CB, Casadesús J, Ramos-Morales F. Rcs and PhoPQ regulatory overlap in the control of Salmonella enterica virulence. J Bacteriol 2007;189:6635-44.

[74] Bock A, Gross R. The BvgAS two-component system of Bordetella spp.: a versatile modulator of virulence gene expression. Int J Med Microbiol 2001;130:119-30.

[75] Ray JCJ, Igoshin O a. Adaptable functionality of transcriptional feedback in bacterial two-component systems. PLoS Comput Biol 2010;6:e1000676.

[76] Wang S. Bacterial Two-Component Systems: Structures and Signaling Mechanisms 2012.

[77] Stock a M, Robinson VL, Goudreau PN. Two-Component Signal Transduction. Annu Rev Biochem 2000;69:183-215.

[78] Gao R, Mack TR, Stock AM. Bacterial response regulators: versatile regulatory strategies from common domains. Trends Biochem Sci 2007;32:225-34.

[79] Galperin MY. Structural classification of bacterial response regulators: diversity of output domains and domain combinations. J Bacteriol 2006;188:4169-82.

[80] Galperin M. Diversity of structure and function of response regulator output domains. Curr Opin Microbiol 2010;13:150-9.

[81] Laub MT, Goulian M. Specificity in two-component signal transduction pathways. Annu Rev Genet 2007;41:121-45. 
[82] Sebaihia M, Peck MW, Minton NP, Thomson NR, Holden MTG, Mitchell WJ, et al. Genome sequence of a proteolytic ( Group I ) Clostridium botulinum strain Hall A and comparative analysis of the clostridial genomes. Genome Res 2007:1082-92.

[83] Shimizu T, Yaguchi H, Ohtani K, Banu S, Hayashi H. Clostridial VirR/VirS regulon involves a regulatory RNA molecule for expression of toxins. Mol Microbiol 2002;43:257-65.

[84] Cheung JK, Keyburn AL, Carter GP, Lanckriet AL, Van Immerseel F, Moore RJ, et al. The VirSR two-component signal transduction system regulates NetB toxin production in Clostridium perfringens. Infect Immun 2010;78:3064-72.

[85] Hiscox TJ, Chakravorty A, Choo JM, Ohtani K, Shimizu T, Cheung JK, et al. Regulation of virulence by the RevR response regulator in Clostridium perfringens. Infect Immun 2011;79:2145-53.

[86] Prigent-combaret C, Brombacher E, Vidal O, Ambert A, Lejeune P, Landini P, et al. Complex Regulatory Network Controls Initial Adhesion and Biofilm Formation in Escherichia coli via Regulation of the csgD Gene Complex Regulatory Network Controls Initial Adhesion and Biofilm Formation in Escherichia coli via Regulation of the csgD Gene 2001.

[87] Ziebandt a K, Weber H, Rudolph J, Schmid R, Höper D, Engelmann S, et al. Extracellular proteins of Staphylococcus aureus and the role of SarA and sigma B. Proteomics 2001;1:480-93.

[88] Sidote DJ, Barbieri CM, Wu T, Stock AM. Structure of the Staphylococcus aureus AgrA LytTR domain bound to DNA reveals a beta fold with an unusual mode of binding. Structure 2008;16:727-35.

[89] Lamarche MG, Wanner BL, Crépin S, Harel J. The phosphate regulon and bacterial virulence: a regulatory network connecting phosphate homeostasis and pathogenesis. FEMS Microbiol Rev 2008;32:461-73.

[90] Dahlsten E, Zhang Z, Somervuo P, Minton NP, Lindström M, Korkeala H. The coldinduced two-component system CBO0366/CBO0365 regulates metabolic pathways with novel roles in cold tolerance of Group I Clostridium botulinum ATCC 3502. Appl Environ Microbiol 2013;80:306-19.

[91] Saujet L, Monot M, Dupuy B, Soutourina O, Martin-Verstraete I. The Key Sigma Factor of Transition Phase, SigH, Controls Sporulation, Metabolism, and Virulence Factor Expression in Clostridium difficile. J Bacteriol 2011;193:3186-96.

[92] Zhang Z, Korkeala H, Dahlsten E, Sahala E, Heap JT, Minton NP, et al. Twocomponent signal transduction system CBO0787/CBO0786 represses transcription from botulinum neurotoxin promoters in Clostridium botulinum ATCC 3502. PLoS Pathog 2013;9:e1003252.

[93] Uehne SA, Heap JT, Cooksley CM, Cartman ST, Minton NP. ClosTron-Mediated Engineering of Clostridium. Yeast 2011;765:389-407. 
804

805

807

808

809

810

811

812

813

814

815

816

817

818

[94] Carter GP, Douce GR, Govind R, Howarth PM, Mackin KE, Spencer J, et al. The antisigma factor TcdC modulates hypervirulence in an epidemic BI/NAP1/027 clinical isolate of Clostridium difficile. PLoS Pathog 2011;7:e1002317.

[95] Sperandio V, Torres AG, Kaper JB. Quorum sensing Escherichia coli regulators B and $\mathrm{C}$ (QseBC): a novel two-component regulatory system involved in the regulation of flagella and motility by quorum sensing in E. coli. Mol Microbiol 2002;43:809-21.

[96] Hammer BK, Bassler BL. Quorum sensing controls biofilm formation in Vibrio cholerae. Mol Microbiol 2003;50:101-4.

[97] Smith RS, Iglewski BH. Pseudomonas aeruginosa quorum sensing as a potential antimicrobial target. J Clin Invest 2003;112:1460-5.

[98] Zhao L, Montville TJ, Schaffner DW. Evidence for quorum sensing in Clostridium botulinum 56A. Lett Appl Microbiol 2006;42:54-8.

[99] Federle M, Bassler B. Interspecies communication in bacteria. J Clin Invest 2003;112:1291-9.

[100] Ohtani K, Hayashi H, Shimizu T. The luxS gene is involved in cell-cell signalling for toxin production in Clostridium perfringens. Mol Microbiol 2002;44:171-9.

[101] Carter GP. Quorum sensing in Clostridium difficile: analysis of a luxS-type signalling system. J Med Microbiol 2005;54:119-27.

[102] Lee ASY, Song KP. LuxS/autoinducer-2 quorum sensing molecule regulates transcriptional virulence gene expression in Clostridium difficile. Biochem Biophys Res Commun 2005;335:659-66.

[103] Đapa T, Leuzzi R, Ng YK, Baban ST, Adamo R, Kuehne S a, et al. Multiple factors modulate biofilm formation by the anaerobic pathogen Clostridium difficile. J Bacteriol 2013;195:545-55.

[104] Waters CM, Bassler BL. Quorum sensing: cell-to-cell communication in bacteria. Annu Rev Cell Dev Biol 2005;21:319-46.

[105] Geisinger E, Adhikari RP, Jin R, Ross HF, Novick RP. Inhibition of rot translation by RNAIII, a key feature of agr function. Mol Microbiol 2006;61:1038-48.

[106] Cooksley CM, Davis IJ, Winzer K, Chan WC, Peck MW, Minton NP. Regulation of neurotoxin production and sporulation by a Putative agrBD signaling system in proteolytic Clostridium botulinum. Appl Environ Microbiol 2010;76:4448-60.

[107] De Kievit TR. Quorum sensing in Pseudomonas aeruginosa biofilms. Environ Microbiol 2009;11:279-88.

[108] Bochner BR, Gadzinski P, Panomitros E. Phenotype MicroArrays for High-Throughput Phenotypic Testing and Assay of Gene Function. Genome Res 2001;11:1246-55. 
839 [109] Loewen PC, Hu B, Strutinsky J, Sparling R. Regulation in the rpoS regulon of Escherichia coli. Can J Microbiol 1998;44:707-17.

841 [110] Toledo-Arana A, Repoila F, Cossart P. Small noncoding RNAs controlling pathogenesis. Curr Opin Microbiol 2007;10:182-8.

843

[111] Chen Y, Indurthi DC, Jones SW, Papoutsakis ET. Small RNAs in the Genus

844 Clostridium. Genus 2011;2:1-11.

845

846 


\section{FIGURE LEGENDS}

Figure 1: Schematic cartoon of the different steps of transcription initiated by RNA polymerase in association with the s70 family. $\square$ factor RNA polymerase is formed by several subunits: two $\square$ subunits which link the two $\square$-subunits and permit the recognition of the activation elements in cis and trans. The two $\square$ subunits allow the linkage to the DNA, RNA synthesis and terminator recognition. The $\square$ factor allows the specific linkage to the promoter region.

Figure 2: Schematic representation of the regulation by Two Component System (TCS). The signal is detected by the SHK (sensor histidine kinase) via its transmembrane domain which leads to a conformational change and an ATP-dependent autophosphorylation on the conserved Histidine $(\mathrm{H})$ residue.

Figure 3: Regulation of the botulinum toxin locus in C. botulinum Hall A by environmental factors and regulatory factors. Factors identified in other $C$. botulinum strains are written in italics. Red arrows correspond to a positive regulation and green arrows correspond to a negative regulation (adapted from [19]).

Figure 4: Schematic representation of the two kinds of quorum sensing communication. Interspecies communication is represented in the left panel. The peptide signal precursor locus is transcribed and translated into a precursor peptide which is cut enzymatically to form small peptides which are the AIPs. AIPs are then transported through the bacterial cell wall by an ABC transporter. AIPs are detected by specific TCSs which regulate target genes. The right panel representes the inter-species communication where AI-2s are produced by LuxS from 
872 SAM and are then passively released into the extracellular medium. AIs are detected by a

873 TCS which regulates specific target genes.

874 


\section{Figure 1}

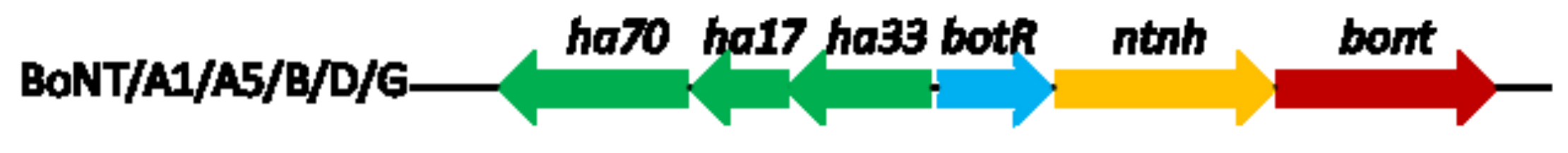

BoNT/C

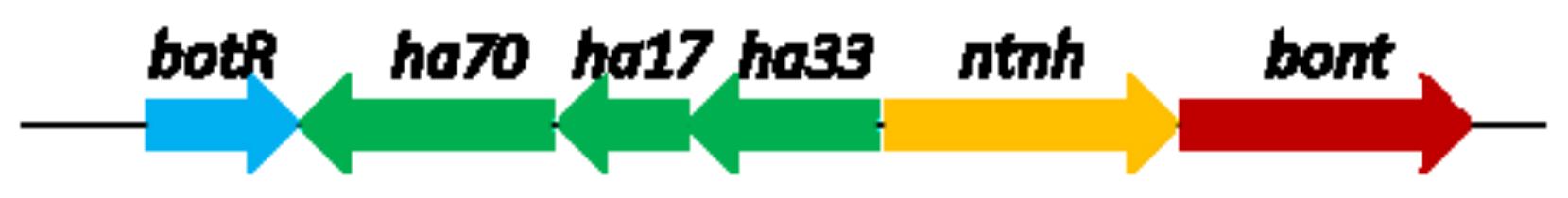

BoNT/E/F

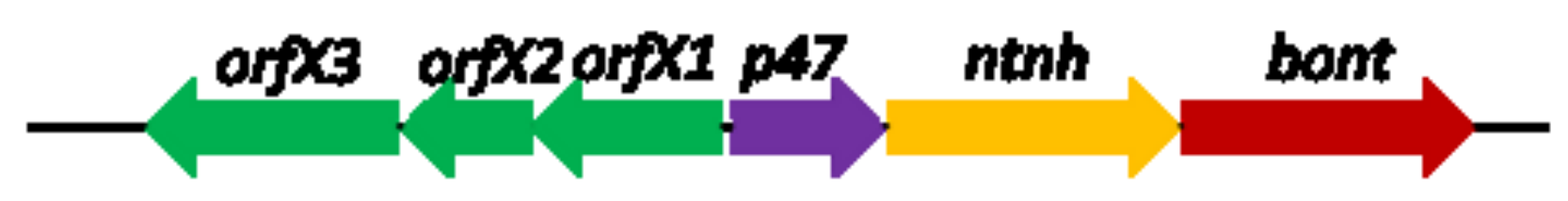

BoNT/A1 to /A4/F orfX3 orfX2 orfX1 is botR p47 ntsh bont 
Figure

Click here to download high resolution image

Finu 2

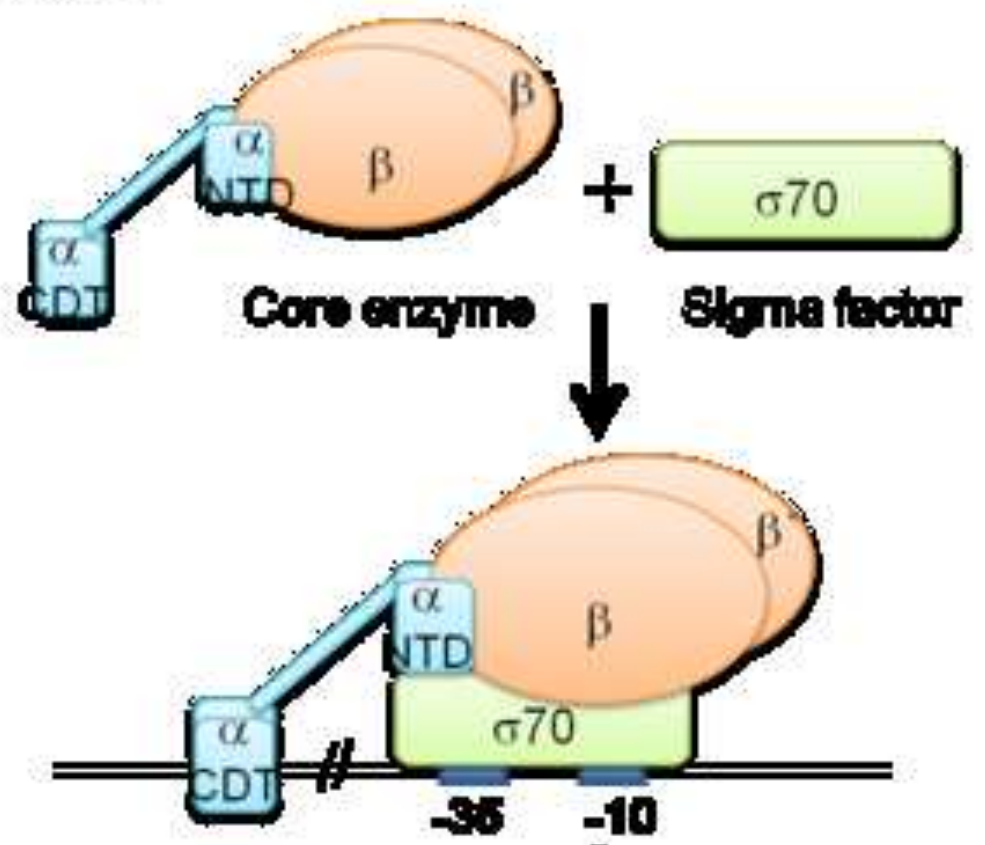

2 Epeciliblhinge to the promoter region of the target gene and formation of the clowed complex

3. bometzation of the closed complex Into an open complex by a local opening of the doublootranded DNA

4. Eynthesis of the first phosphodlester bond Abortwe 5. Smtheals of non RNA produotwo oligomers

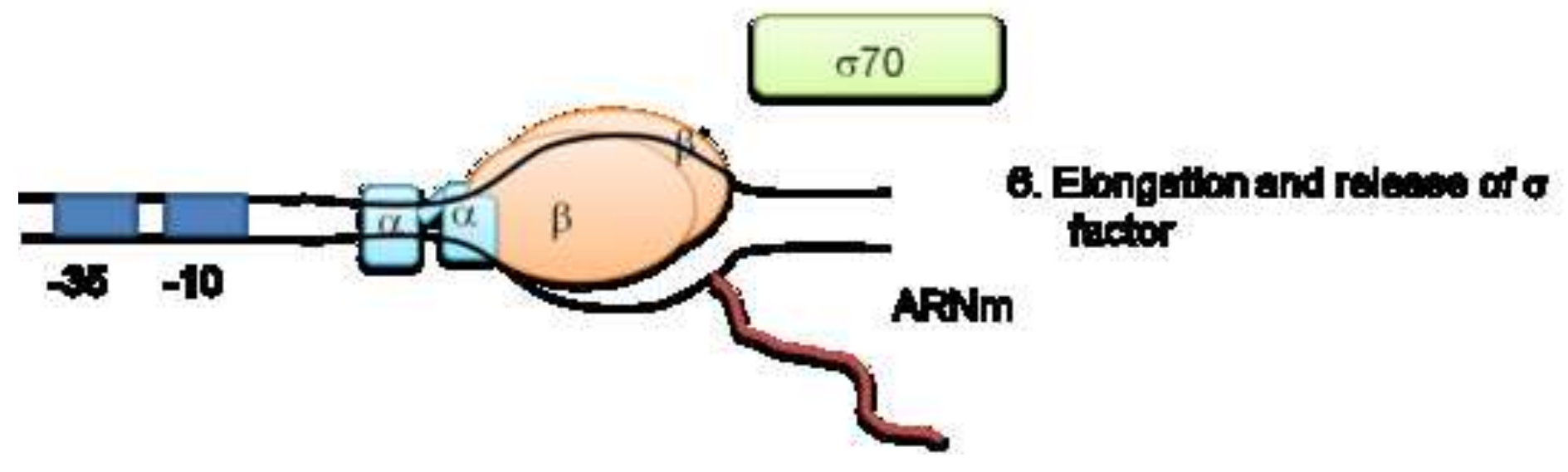




\title{
Fgure 3 \\ Mrre
}

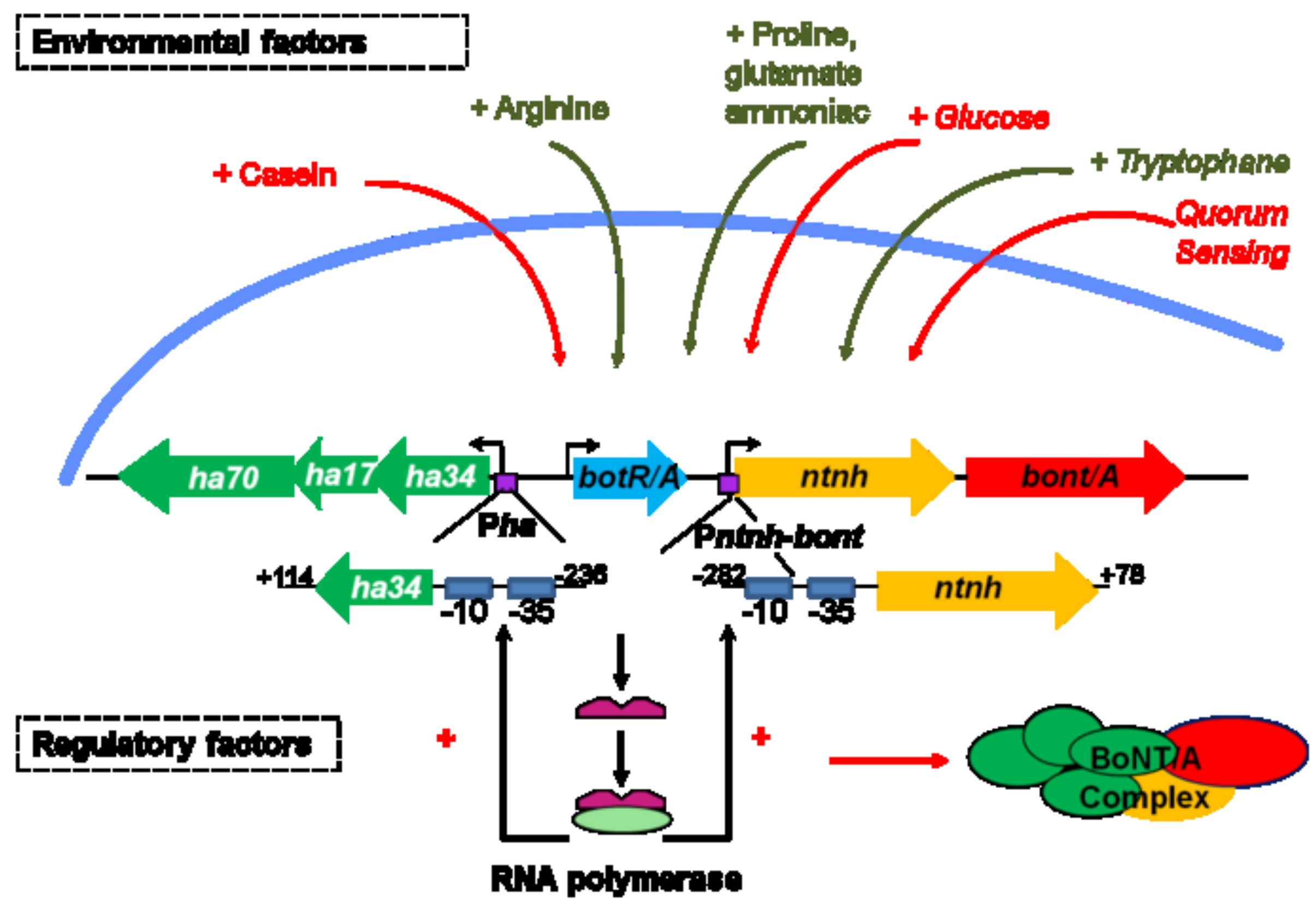

[Eivronmental trators

Reorlotory factors

RWA pohmoreso

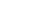


Flgure 4

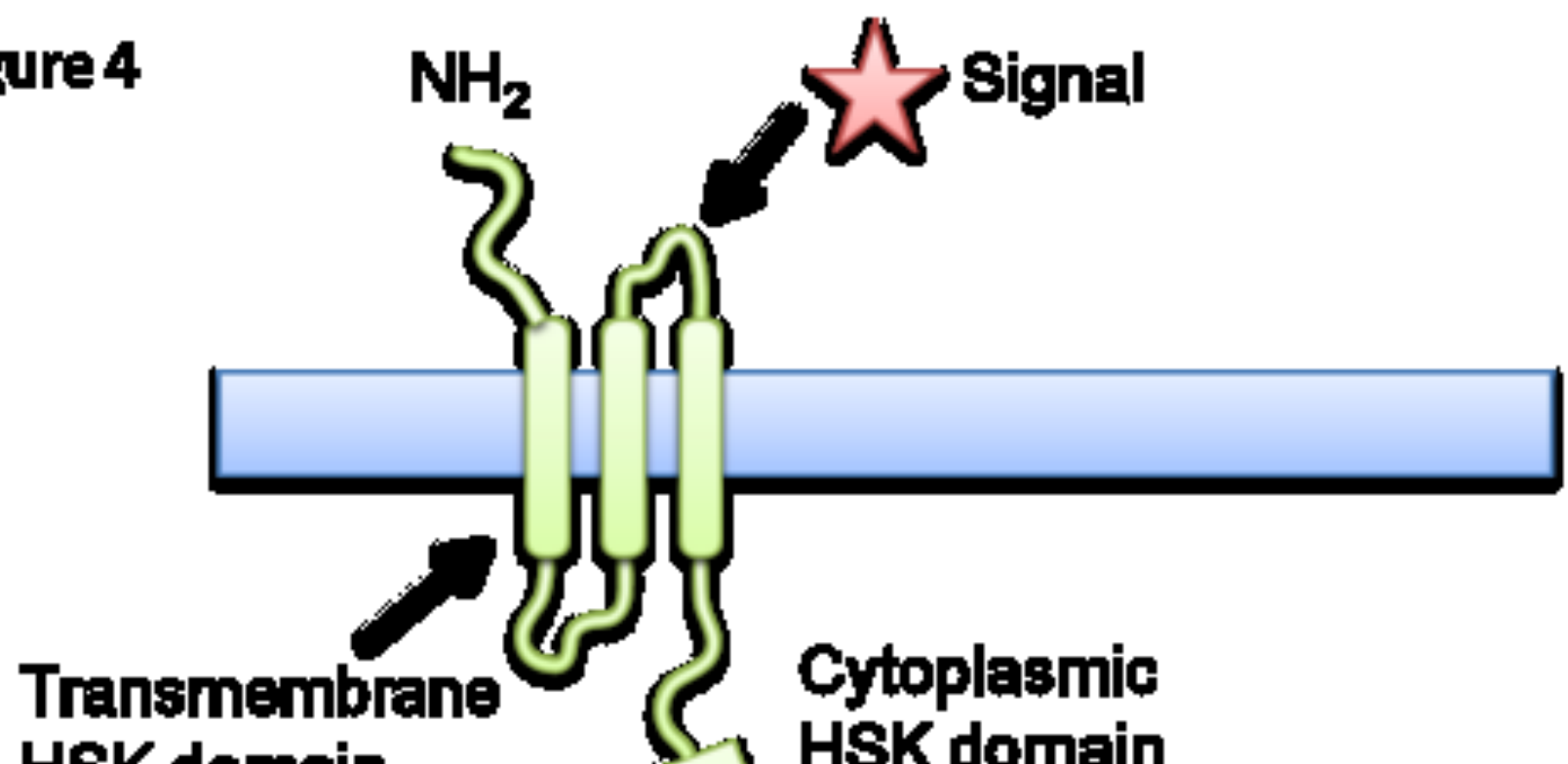

Transmembrane

Cell membrane HSK domain

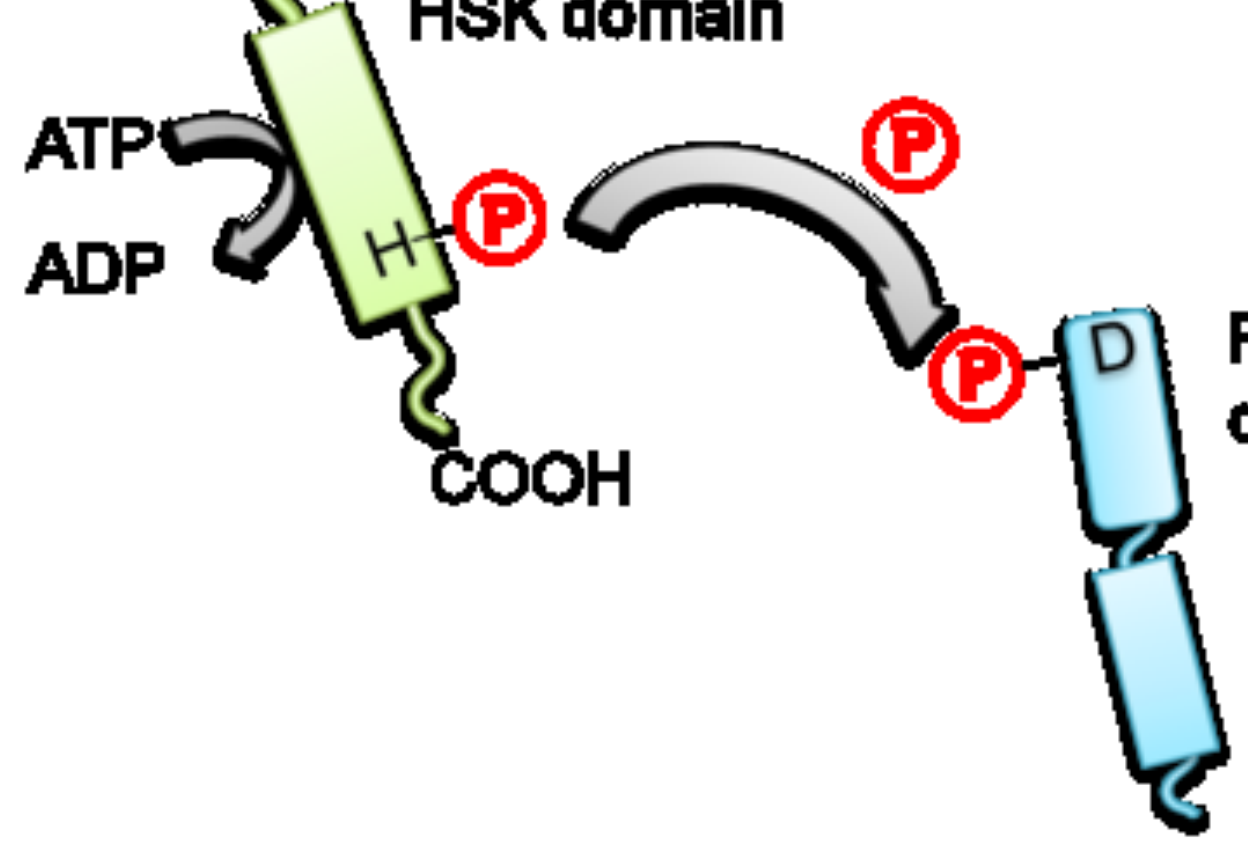

RR effector domain

RR recoptor domaln

Action on one or several target genes

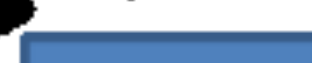




\section{Figure 5}

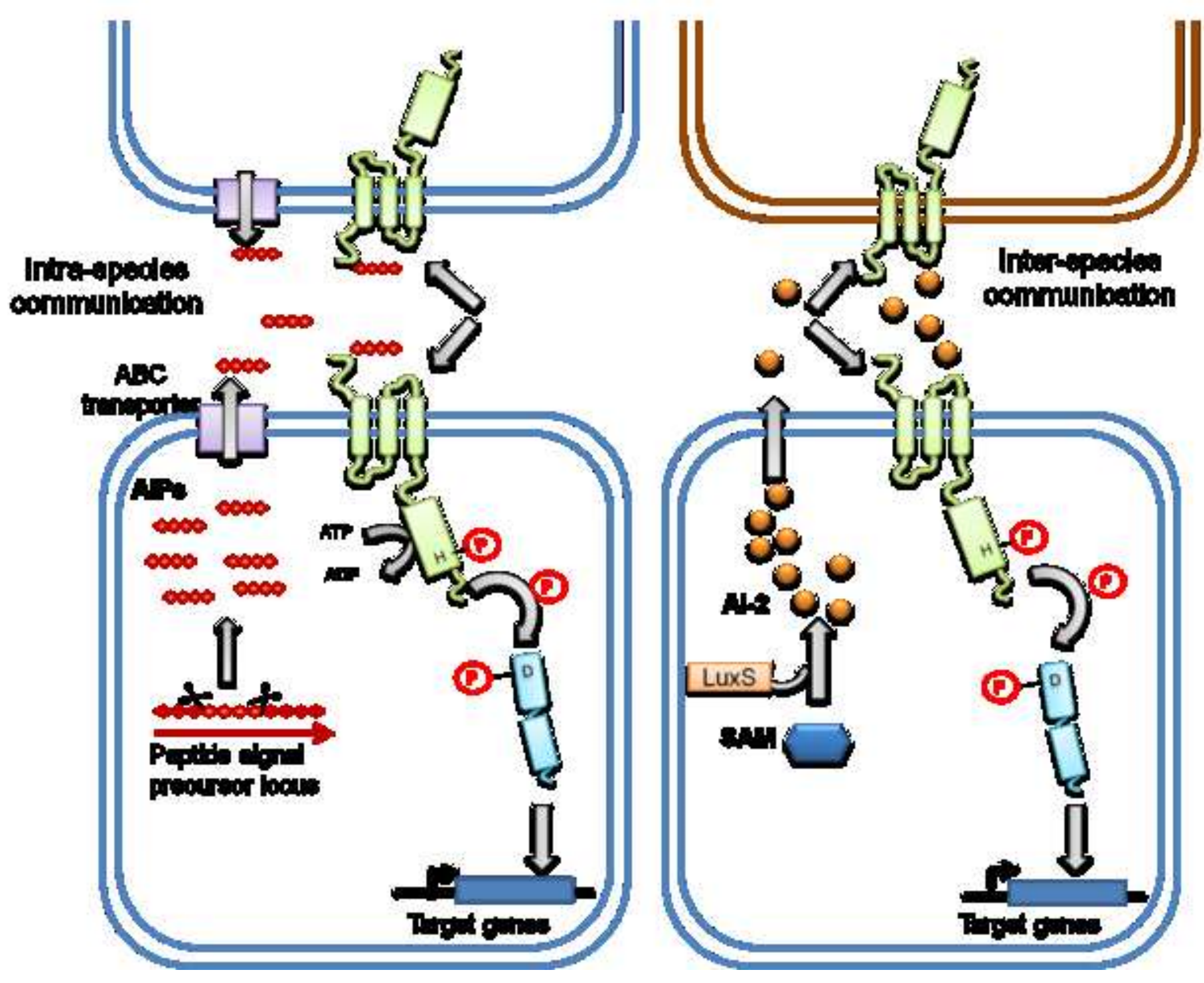

